\title{
ANÁLISE DO DESENVOLVIMENTO DO CURSO FIC EM INSTALAÇÕES ELÉTRICAS PREDIAIS DO IFRJ DE SÃO JOÃO DO MERITI
}

\author{
ANDRÉ TIAGO SANTOS ${ }^{1}$; ALAN TAVARES MIRANDA ${ }^{2}$; ALEXANDRE DA \\ SILVA BARCELLOS ${ }^{3}$; DANIEL FERNANDES DA CUNHA VERAS ${ }^{4}$
}

\begin{abstract}
${ }^{1}$ Mestre em Automação e Controle de Processos pelo Instituto Federal de São Paulo (IFSP), Graduado em Engenharia de Automação e Controle pela Universidade Braz Cubas (UBC), Professor no Instituto Federal do Rio de Janeiro (IFRJ), São João de Meriti - RJ. e-mail: andre.tiago@ifrj.edu.br;

${ }^{2}$ Mestre em Eng. Eletrônica pelo Centro Federal de Educação Tecnológica do Rio de Janeiro (CEFET RJ), Especialista em Engenharia de Segurança do Trabalho pela Universidade Federal Fluminense (UFF), Graduado em Engenharia Eletrônica pelo Centro Federal de Educação Tecnológica do Rio de Janeiro (CEFET - RJ), Professor no Instituto Federal do Rio de Janeiro (IFRJ), São João de Meriti - RJ. e-mail: alan.tavares@ifrj.edu.br;

3 Especialista em Gestão de Projetos pelas Faculdades Signorelli, Rio de Janeiro, Graduado em Engenharia Elétrica pela Universidade Veiga de Almeida (UVA), Professor no Instituto Federal do Rio de Janeiro (IFRJ), São João de Meriti - RJ. e-mail: alexandre.barcellos@ifrj.edu.br;

4 Especialista em Gestão de Projetos pelas Faculdades Signorelli ,Rio de Janeiro, Graduado em Engenharia Elétrica pela Universidade do Estado do Rio de Janeiro (UERJ), Professor no Instituto Federal do Rio de Janeiro (IFRJ), São João de Meriti - RJ. e-mail: daniel.veras@ifrj.edu.br.
\end{abstract}

\section{RESUMO}

O presente artigo apresenta algumas reflexões acerca do desenvolvimento do Plano Político e Pedagógico do Curso Instalações Elétricas Prediais de Baixa Tensão, modalidade Formação Inicial e Continuada, proposto pelo Instituto Federal do Rio de Janeiro para a cidade de São João de Meriti. Neste texto, buscou-se analisar quais seriam os conteúdos mais adequados para a formação pretendida em observância, não somente aos aspectos técnicos e interdisciplinares, mas também atender a necessidades de formação mais ampla, consonante com os aspectos socioeconômicos do públicoalvo. Além disso, foram propostas metodologias de ensino para todas as disciplinas que compõem o curso.

Palavras-chave: Projeto Político Pedagógico; Instalações Elétricas; Formação Inicial e Continuada.

\section{FIC COURSE DEVELOPMENT ANALYSIS IN SÃO JOÃO DO MERITI PREDIAL ELECTRICAL INSTALLATIONS}

\begin{abstract}
This paper presents some reflections on the development of the Pedagogical Political Project of the Low Voltage Building Electrical Installations Course, Initial and
\end{abstract}


Continuous Formation modality, proposed by the Federal Institute of Rio de Janeiro for the city of São João de Meriti. In this text, one tried to analyze what would be the most appropriate content for the intended training in compliance not only with technical and interdisciplinary aspects, but also meet the needs of broader training, in line with the socioeconomic aspects of the target audience. In addition, teaching methodologies were proposed for all the subjects that make up the course.

Keywords: Political Pedagogical Project; Electrical Installations; Initial and Continuing Training.

\section{INTRODUÇÃO}

O papel de favorecer o desenvolvimento local e regional constitui-se como dever dos Institutos Federais de Educação. Isso parte da interação entre esta instituição e a região na qual está estabelecida, buscando uma aproximação de seus interesses com a realidade local (PACHECO, 2010). Tal processo se inicia através da determinação dos eixos tecnológicos do Campus que, no caso do Instituto Federal do Rio de Janeiro (IFRJ) de São João de Meriti (SJM), ocorreu por meio de uma audiência pública realizada em 2016. Nesse evento, a população local optou por três eixos, respectivamente, em ordem de colocação: Administração, Informática e Eletrotécnica.

A equipe de eletrotécnica elaborou um Plano Político de Curso (PPC), na modalidade de Formação Inicial e continuada (FIC), em Instalações Elétrica em Baixa Tensão (IEBT), pertencente ao catálogo do Programa Nacional de Acesso ao Ensino Técnico e Emprego (PRONATEC). Para a elaboração desse curso, foi necessário traçar o perfil do egresso, alinhado com uma ementa básica que atendesse às qualificações exigidas no mercado de trabalho para empregabilidade nos setores industrial e comercial, bem como prestação de serviços como autônomo. Dessa forma, couberam os seguintes questionamentos: quais deveriam ser as principais habilidades a serem adquiridas pelos discentes e em quais nichos de mercado eles deveriam estar qualificados para atuar?

A fim de nortear as respostas para essas dúvidas, as pesquisas realizadas objetivando conhecer o perfil dos profissionais eletricitários de SJM mostraram que, de acordo com o censo amostral para o trabalho da cidade de São João de Meriti apresentado pelo IBGE em 2010, a população apresentava apenas 0,073\% do número de indivíduos atuantes em serviços de eletricidade e gás. Esse número é relativamente 
baixo quando comparado a cidades vizinhas tais quais como Rio de Janeiro, Duque de Caxias e Nova Iguaçu, que apresentam, respectivamente, 0,3983\%, 0,1279\% e 0,1453 (IBGE, 2011).

Além disso, outras preocupações com o delineamento profissional do discente estavam relacionadas a alguns problemas recorrentes na indústria da construção civil, um dos importantes segmentos de atuação para os profissionais eletricitários (e.g. formação escolar inferior aos profissionais de outros setores). Costa e Tomasi (2009) afirmam que cerca de $60 \%$ dos trabalhadores deste setor apresentam baixo índice de escolaridade e $10 \%$ deles apenas assinam o nome, o que pode prejudicar a produção, além de comprometer a qualidade dos serviços.

Ainda segundo Picchi e Agopyan (1993), ao comparar a indústria da construção civil e a indústria metal mecânica ou a indústria têxtil, percebe-se um atraso no gerenciamento, na racionalização e no incremento dos processos produtivos. Enquanto a indústria automobilística gasta 100 horas de trabalho de um operário para a produção de uma unidade, a construção civil gasta 2000 horas e a quantidade de empregados para a produção anual na construção é seis vezes maior que o da indústria automobilística, conforme Souza (2006). Desse modo, é importante refletir sobre a relação entre a qualificação da mão de obra e a eficiência produtiva.

Outro problema recorrente na indústria da construção civil são os acidentes de trabalho que põem em risco a integridade física e a saúde dos profissionais. No triênio 2013, 2014 e 2015, este setor teve representatividade de 7,51\%, o que correspondeu ao valor absoluto de 154.082 do total de 2.050.598 (FILHO; PONTES, 2018). Cabe destacar que, de acordo com último Anuário Estatístico de Acidentes do Trabalho (AEAT), publicado pela Previdência Social, houve uma queda de 7\% no número total de acidentes no país; no entanto, muito ainda se deve melhorar em termos de segurança laboral, uma vez que, de acordo com Pinto (2017), o Brasil se encontra em quarto lugar no ranking mundial de acidentes de trabalho com óbito, sendo antecedido apenas pela China, Estados Unidos e Rússia (BRASIL, 2018).

O PPC do curso FIC em IEBT foi criado a fim de atender às necessidades do município quanto ao baixo efetivo de profissionais na área de eletricidade, tendo em vista, em especial, a segurança laboral desses profissionais, haja vista as estatísticas apresentadas. Aliás, pretende-se melhorar a formação desse profissional em âmbito mais 
amplo, considerando-se não somente a qualificação técnica, mas adicionalmente o desenvolvimento ético-cidadão e empreendedor.

O curso desenvolvido tem bases legais na Lei 11.892/2008 que versa sobre os cursos e programas de Formação Inicial e Continuada de profissionais ofertados pelos Institutos Federais de Educação. Tais cursos objetivam capacitação, aperfeiçoamento, especialização e atualização em todos os níveis educacionais, nos segmentos da educação profissional e tecnológica (BRASIL, 2011). A formação em eletricista, por meio de FIC, também é ofertada em outros Institutos Federais (IF), como no Pará e em Santa Catarina. Observou-se que os seus PPC's apresentam, em linhas gerais, ementas parecidas, ratificando preocupações similares relacionadas à formação desses profissionais.

Dentre os principais pontos estão as disciplinas de núcleo comum, como Matemática, Ética e Cidadania e Empreendedorismo, e de núcleo específico, como Instalações Elétricas, Medidas Elétricas e Segurança do Trabalho. Busca-se, assim, compor uma formação ampla tanto no contexto social quanto técnico, tendo em vista que os alunos terão como um dos principais campos de atuação a construção civil ou a prestação de serviços como autônomo.

Neste sentido, o objetivo principal deste trabalho é mostrar o desenvolvimento do PPC do curso FIC em IEBT Prediais nos aspectos da formação discente no contexto da cidade de São João de Meriti e adjacências, situado no estado do Rio de Janeiro.

Estruturalmente, tem-se os seguintes objetivos secundários:

- Levantamento bibliográfico de documentos científicos e relacionados, tangentes à temática FIC;

- Abordagem do desenvolvimento do Projeto Político Pedagógico do curso FIC em Instalações Elétricas Prediais, ressaltando a relevância interdisciplinar;

- Propostas metodológicas referentes às aulas das disciplinas que compõem o curso FIC.

\section{REVISÃO BIBLIOGRÁFICA}

Nesta subseção, é apresentada a revisão de literatura, no sentido de se mostrar as pesquisas feitas em razão da implementação de cursos FIC, da metodologia 
empregada, das discussões tidas no plano da formação profissional, dos resultados pontuais obtidos e das conclusões e inferências tomadas em convergência com os objetivos propostos. Segue-se, destarte.

O objetivo do trabalho dos autores Costa e Costa (2015) foi conhecer as especificidades dos alunos do curso Programa Nacional de Integração da Educação Profissional com a Educação Básica na Modalidade de Educação de Jovens e Adultos na modalidade de Formação Inicial e Continuada (PROEJA-FIC), do campus de Araranguá, Instituto Federal de Santa Catarina. A metodologia de pesquisa empregada foi a aplicação de um questionário com perguntas objetivas para 10 alunos. Para a análise dessas respostas obtidas, utilizou-se um padrão de contagem, sendo os resultados apresentados em forma de gráficos. A maioria dos alunos é do gênero masculino (80\%), casados, ocupantes da faixa etária de 41 a 50 anos, empregados, oriundos de escolas públicas, afastados da escola há mais de 12 anos, tendo cessado os estudos para trabalhar. Segundo eles, voltaram para a escola em busca de um futuro melhor e atraídos pela qualidade de ensino do IFSC. Como empecilhos para a realização do curso, encontraram dificuldades em algumas disciplinas e apontaram, em função da afinidade, no curso, foram os conhecimentos adquiridos. Rematando, 70\% dos alunos pretendem realizar um PROEJA de ensino médio após o término do curso.

O trabalho elaborado por Souza (2016) versou sobre o Programa Nacional de Acesso ao Ensino Técnico e Emprego (PRONATEC), desenvolvido pelo Governo Federal no ano de 2011 e instituído, tendo por objetivo a ampliação da oferta de cursos de educação profissional e tecnológica. O objetivo geral deste trabalho foi avaliar a efetividade dos principais cursos de curta duração do IFSC por meio de um benchmarking com os cursos técnicos de longa duração da região Sul do Brasil. Em específico, a qualidade entre os cursos de curta e longa duração e a situação dos seus egressos quanto à empregabilidade e continuidade dos estudos foi comparada.

Ainda, conforme Souza (2016), os dados, a partir da aplicação de questionário e os métodos empregados se seguem: análise de conteúdo, testes do Qui-Quadrado e U de Mann-Whitney, foram obtidos. As porcentagens dos egressos dos cursos de curta ou longa duração empregados foram iguais; porém, nos cursos de longa duração, o número de egressos que trabalham na área de formação foi 
estatisticamente maior, os resultados indicaram. Além disso, os egressos dos cursos de longa duração, deslocando-se para encontrar trabalho, ocuparam empregos em diferentes regiões do Brasil, apresentando uma maior mobilidade.

Assim, em consonância com Souza (2016), em relação à continuidade dos estudos, os egressos dos cursos de longa duração apresentaram uma maior continuidade e, enquanto esses buscaram cursos de nível superior, a maioria dos egressos dos cursos de curta duração procurou outros cursos técnicos de nível médio. Em geral, a percepção quanto à qualidade dos cursos pelos diferentes egressos analisados, em sua maioria, foi considerada entre boa e ótima.

O artigo proposto por Oliveira e Miranda (2017) fez parte de uma pesquisa de mestrado concluída, cujo objetivo foi identificar o papel do Programa Nacional de Acesso ao Ensino Técnico e Emprego (PRONATEC) no campo das políticas de formação profissional tomando como campo de pesquisa o Instituto Federal (IF) do Sudeste de Minas Gerais, campus Muriaé, tendo em vista que a instituição é ofertante do PRONATEC desde 2012 e, atualmente, oferece o MEDIOTEC, programa do governo que oferece cursos técnicos simultâneos ao ensino médio.

Ainda, de acordo com Oliveira e Miranda (2017), com a finalidade de compreender o objetivo, consubstanciam-se os estudos nas políticas de formação profissional a partir da década de 1990, como o Plano Nacional de Qualificação do Trabalhador (PLANFOR), o Plano Nacional de Qualificação (PNQ) e o PRONATEC, identificando as perspectivas e os desafios dessas políticas para a área de formação dos trabalhadores. Nessa esteira de discussão, problematizou-se também o atual projeto de formação profissional que se efetivará por meio do PRONATEC e o MEDIOTEC que é a nova ação do primeiro e dá prioridade à oferta de cursos técnicos em concomitância ao ensino médio regular para estudantes matriculados em escolas públicas.

E, dessa forma, perfazendo o trabalho de Oliveira e Miranda (2017), encontrou-se, na pesquisa, os limites desses projetos que mais convergem com a perspectiva de ampliação do capital do que com os interesses da classe trabalhadora.

A dissertação proposta por Folgado (2015) tem como objeto de estudo as práticas docentes em cursos de FIC ofertados pelo PRONATEC. Os desafios enfrentados pelos professores para implementar uma prática pedagógica adequada ao 
atendimento do público desse programa, muitos são caracterizados por grande heterogeneidade cultural e educacional. Práticas docentes referem-se às atividades de trabalho de professores e pela organização, condução e controle das atividades de aprendizagem de alunos, constituindo, também, essas atividades de trabalho. Tantas as atividades, docentes e discentes, são educacionais e, mutuamente, condicionadas; relativamente e intencionalmente orientadas. São sempre atividades situadas, pois se referem a contextos sociais e culturais determinados historicamente. Para se executarem, requerem reflexão, criatividade, autocrítica e contínua construção. As práticas docentes dependem da participação ativa e engajada dos alunos no desenvolvimento das suas próprias aprendizagens e autonomia pessoal. Para tanto, precisam estimulá-los a fazer associações entre as novas aquisições e aprendizagens anteriores, conexões com suas experiências e vivências, combinações, reconstruções e ressignificações de conhecimentos e saberes. O Governo Federal, por meio do Ministério de Desenvolvimento Social (MDS) e do Ministério da Educação (MEC), tem feito grandes investimentos no Pronatec, programa criado pela Lei Federal $n^{\circ}$ 12.513/11, que tem forte potencial de estímulo ao desenvolvimento local. Dentre seus objetivos, propõe expandir e democratizar o acesso à Educação Profissional e Tecnológica (EPT) por meio da oferta gratuita do ensino técnico e de cursos de formação inicial e continuada (FIC) e benefícios de assistência estudantil. Esta dissertação se compõe de revisão bibliográfica sobre práticas docentes e, em especial, na educação profissional e tecnológica; de relatório de pesquisa realizada no campus São João del-Rei do Instituto Federal de Educação, Ciência e Tecnologia do Sudeste de Minas Gerais (IFSEMG) e de uma contribuição técnica.

A pesquisa de Folgado (2015) considerada empírica, possui caráter exploratório e descritivo; teve, bem como abordagem metodológica qualitativa e se valeu de estudos bibliográficos e documentais, de técnicas de entrevista e de observação direta. A contribuição técnica, ensejada pelos resultados da pesquisa realizada, trata de material didático destinado à formação continuada de professores que atuam em cursos de formação inicial e continuada, enfatizando-se, especialmente, formas de organizar, conduzir e controlar as atividades de aprendizagem de alunos, considerando-se os desafios inerentes à educação de jovens e adultos, tais como 
defasagens na escolarização e a diversidade educacional e cultural dos alunos, assim como os relativos à formação profissional desse público.

\section{METODOLOGIA}

O método científico empregado foi o dedutivo, pois utiliza sequências de raciocínios descendentes a fim de atingir os objetivos propostos; assim, esta pesquisa caracterizou-se da seguinte maneira: aplicada, qualitativa, exploratória, descritiva e bibliográfica. Sob a perspectiva de sua natureza, a pesquisa foi aplicada, porque objetivou a construção de conhecimento para aplicação prática, dirigidas às análises acerca do desenvolvimento do PPC e das dificuldades na construção do principal ambiente didático: o laboratório de instalações elétricas prediais; utiliza-se da investigação de dados disponíveis na literatura especializada relacionada ao tema proposto, não necessitando, para tal, do uso de técnicas estatísticas. Portanto, a pesquisa é qualitativa.

Quanto aos objetivos, a pesquisa é exploratória, pois não se pretende verificar teorias, objetiva-se proporcionar maior familiaridade com o problema. Ademais, sob o mesmo ponto de vista, este estudo é descritivo, haja vista que objetiva descrever as características do PPC, do laboratório no Contexto do Campus de São João de Meriti. Já sob a ótica dos procedimentos técnicos utilizados, este artigo utiliza a pesquisa bibliográfica para embasar seus propósitos.

A fim de atender aos propósitos deste artigo, inicialmente, realizou-se uma revisão bibliográfica sobre a temática FIC para posterior abordagem sobre a concepção do PPC. As disciplinas que compõe a ementa foram divididas em dois eixos temáticos: formação profissional e geral.

Assim, será mostrado a seguir, pontos sobre o desenvolvimento do PPC, quanto à sua concepção e breve descrição dos conteúdos programáticos. Além disso, algumas propostas metodológicas para as disciplinas do curso serão apresentadas.

\section{DESENVOLVIMENTO DO PPC}


O curso foi criado para atender ao baixo número de profissionais do setor elétrico na cidade de SJM, oferecer à sua população qualificação técnica gratuita que possibilitasse aos egressos do curso empregabilidade na indústria ou setor afim, bem como possibilitar a atuação por iniciativa própria, empreendendo o seu próprio negócio. O PPC em IEBT foi inicialmente pensado levando-se em consideração que, dentre as instituições públicas de ensino profissionalizante como IFRJ, CEFET-RJ e FAETEC, sendo essa última a única que oferece o curso de IEBT, que possui duas unidades que oferecem esse curso: Unidade Parque Araruama e Unidade Vilar dos Teles. As tais unidades, localizadas em São João de Meriti, têm quantitativo insuficiente para atender uma população de 471.888 pessoas (IBGE, 2019); com isso, faz-se necessária a implantação de mais um curso gratuito de Eletricista Predial de Baixa Tensão, já que a maior parte da população meritiense não tem renda suficiente para custear esse curso numa unidade de ensino privado.

Então, num segundo momento, pensando-se nas disciplinas que pudessem contemplar tanto a formação específica na área de elétrica quanto a geral, a ementa foi elaborada a fim de cumprir uma carga horária de 162 horas. As disciplinas específicas definidas foram: Instalações Elétricas e Eletricidade Básica; Medidas Elétricas e Segurança do Trabalho. Para uma formação geral, as disciplinas definidas para ementa foram: Empreendedorismo e Ética e Cidadania.

As disciplinas de formação específica foram construídas a partir da análise de outros PPC's e da experiência trazida pelos membros da equipe. É importante observar que foi preciso elaborar uma ementa para as disciplinas específicas, no qual fosse possível compatibilizar o conteúdo teórico com a prática, considerando-se que o laboratório ainda estava em processo concepção e montagem e os recursos disponíveis eram escassos.

Em 2017, ano de construção do PPC, havia instabilidade política no país e os Institutos Federais foram consideravelmente restringidos. Segundo dados do Conselho Nacional das Instituições da Rede Federal de Educação Profissional, Científica e Tecnológica (CONIF, 2016) referentes aos recursos de custeio, em 2017, seriam necessários para a garantia das atividades institucionais $\mathrm{R} \$ 3,7$ bilhões, sendo aprovado pelo MEC o valor de apenas R \$ 2,1 bilhões, mesmo havendo, entre os anos de 2012 a 2015, aumento do número de campi e matrículas. Essa diminuição afetou, 
principalmente os campi onde os números de discentes aumentaram, devido ao planejamento de abertura realizada pelo próprio MEC, CONIF e Reitorias, a partir das demandas, reivindicações da sociedade e disponibilidade de servidores. Os cortes de verbas de capital afetaram principalmente os campi em construção, da última fase de expansão da Rede Federal e alguns campi que estavam melhorando suas estruturas (SEGUNDO; MARTINS, 2018).

\section{CONSTRUÇÃO DA EMENTA: FORMAÇÃO PROFISSIONAL}

\subsection{Disciplina: Eletricidade Básica e Instalações Elétricas}

Para o conteúdo da disciplina Eletricidade Básica e Instalações Elétricas, refletiu-se sobre a importância entre os conceitos físicos teóricos da eletricidade e a suas implicações práticas nas instalações elétricas. A carga horária da disciplina foi definida como 54 horas, sendo a maior e principal do curso.

A metodologia de ensino definida consiste em aulas teóricas sobre os tópicos de eletricidade básica e instalações elétricas, em que são apresentados os fundamentos relevantes para o seu entendimento e, quando aplicáveis, exercícios teóricos resolvidos em sala de aula, com a finalidade de estimular o debate, a troca de conhecimentos e a reflexão a respeito do conteúdo aprendido e suas possíveis consequências práticas.

Por fim, foram planejados exercícios práticos no laboratório, após a assimilação de determinados tópicos. A ementa possui itens como grandezas elétricas fundamentais; lei de Ohm; eletromagnetismo; dispositivos elétricos; circuitos; previsão de cargas para iluminação, pontos de tomada de uso geral e específicos; simbologias; divisão de circuitos; dimensionamento de componentes; sistemas de proteção contra choques elétricos e surtos.

Para o desenvolvimento dos discentes em relação à aplicação do conhecimento adquirido, foi criado o laboratório de instalações elétricas prediais. A presença deste ambiente é fundamental para consolidar a formação do conhecimento do discente, isso ocorre por meio do desenvolvimento de habilidades práticas e da interpretação de ações e procedimentos. Com isso, o laboratório possui grande importância para consolidação do conhecimento e para aproximação da realidade do cotidiano (AMARAL et al.,2011). 
Para isso, foi projetado um espaço com seis baias equipadas com diversos itens encontrados em instalações elétricas prediais e/ou comerciais convencionais, simulando, alguns pontos elétricos de edificações e equipamentos. A primeira etapa para a construção do laboratório foi refletir sobre um layout no qual fosse possível criar um espaço bastante próximo dos ambientes de construção e/ou manutenção de edificações, conjugado com a sala de aula, pois, tanto as aulas teóricas quanto práticas, deveriam ocorrer no mesmo local. Era necessário que, nesse ambiente, existisse infraestrutura de modo que, nas atividades práticas, fosse possível a passagem de fios, instalações de tomadas, luz e outros equipamentos, de maneira fidedigna com a realidade, sem comprometer o espaço destinado às aulas teóricas. Uma vez superada esta primeira etapa, era necessário pensar sobre os materiais e os equipamentos que iriam compor toda a estrutura para que se pudessem simular as instalações e/ou manutenções em sistemas elétricos prediais.

As práticas foram desenvolvidas segundo nível crescente de complexidade, de tal maneira que não se tornassem frustrantes pela dificuldade e nem desmotivadoras pela trivialidade, contemplando as ações necessárias para a apreensão do conteúdo pelo discente. Tais atividades iniciam-se pela instalação de simples pontos de iluminação, em ordem crescente de número, com o aprendizado de comandos em paralelo, em que evolui até a instalação de iluminarias que possuem reatores.

Em seguida, os discentes terão acesso às práticas relacionadas as instalações de tomadas de corrente em tensões elétricas convencionais, capacitando-os a instalá-las para os diversos aparelhos existentes, priorizando o sistema de aterramento para a segurança das pessoas e equipamentos. Em relação aos dispositivos de proteção, foram planejadas ações no caminho de facilitar o entendimento acerca das aplicações dos seguintes equipamentos: disjuntor termomagnético, disjuntor diferencial residual e dispositivo de proteção contra surto. Tais práticas visam preparar o discente para a montagem de instalações seguras. Por encerramento, foram concebidas apresentações de práticas relacionadas à instalação de bomba d'água utilizando acionamentos elétricos ordinários como chaves automáticas de boia e contatoras.

No desenvolvimento das aulas práticas, estão previstos quatro discentes por baia, realizando as atividades em duplas. Esse procedimento visa a adequação ao mercado de trabalho, já que é sugerido que os eletricistas, por questões de segurança, trabalhem em 
equipe, sendo que, em certos casos, é vedado o trabalho individual como no caso de atividades em alta tensão, de acordo com a Norma Regulamentadora N.10. Para conduzir as aulas, como estratégia, estarão presentes dois professores que orientarão os alunos nas práticas e os ajudarão no processo de aprendizado. Como efeito, diminui-se o número de alunos por professor $\mathrm{e}$, consequentemente, pretende-se melhorar $\mathrm{o}$ atendimento aos grupos sob sua orientação, agregando mais valor nas relações sociais, possibilitando maior aproximação dos discentes aos professores e, com isso, maior troca de conhecimentos.

\begin{abstract}
Concretamente pensando, a construção do conhecimento não pode ser entendida como algo individual. $\mathrm{O}$ conhecimento é produto da atividade e relações humanas marcado social e culturalmente. Pensando a relação professor/aluno, o professor tem um importante papel que consiste em agir como intermediário entre os conteúdos da aprendizagem e a atividade construtiva para assimilação dos mesmos (BRAIT et al., 2010, p. 4).
\end{abstract}

Foi planejada a distribuição de kits de ferramentas para os grupos de alunos, juntamente com o roteiro de aula para interpretação e a execução das tarefas sob constante supervisão e orientação docente. Assim, pretende-se simular situações em que o eletricista recebe o projeto a ser executado e procede a sua realização sob orientação de um encarregado técnico.

A complementação técnica dos diversos saberes importantes à formação do profissional eletricitário ocorre, neste curso, através das disciplinas de Medidas Elétricas e Noções de Segurança do Trabalho e Saúde Ocupacional, ambas com cargas horárias de 27 horas.

\title{
5.2 Disciplina: Medidas elétricas
}

Através da disciplina de Medidas Elétricas, pretende-se apresentar aos alunos técnicas matemáticas fundamentais, cuja finalidade é aperfeiçoar o entendimento acerca dos conceitos físicos da eletricidade, variáveis elétricas e suas dimensões. Além disso, o manuseio de equipamentos de medição e algumas técnicas de testes em sistemas elétricos são temas em destaque.

De maneira mais específica, essa disciplina trata do uso dos instrumentos e aparelhos de medição das variáveis elétricas principais (e.g. tensão, corrente e resistências elétricas). Os equipamentos que mensuram essas grandezas são 
respectivamente: voltímetro, amperímetro e ohmímetro (CAPUANO; MARINO, 2007). O multímetro reúne todos os medidores citados anteriormente, entretanto, o mais indicado para o trabalho do eletricista é o aparelho alicate-amperímetro (BRAGA, 2005).

A metodologia de ensino e aprendizagem para a disciplina de Medidas Elétricas foi planejada para se consolidar através de aulas expositivas, de introdução teórica e conceitual sobre determinada unidade didática; atividades dinâmicas realizadas em equipe e/ou individuais, dependendo da necessidade de mediação/intervenção do docente e; atividades práticas laborais, consolidando-se o ponto aprendido na unidade em questão com a observação de experimentos físicos das medidas elétricas.

A sequência didática que foi formulada para esta disciplina prevê que os estudantes revisem tópicos de matemática básica que estejam relacionados aos conceitos das dimensões e medidas elétricas, bem como seus respectivos instrumentos. Desse modo, ao se introduzir as unidades de matemática básica, como por exemplo, porcentagens, razões e equações do $1^{\circ}$ grau, promove-se a resolução de problemas que envolvam tais assuntos e constroem-se noções de variação das grandezas para a compreensão da realidade e solução de problemas do cotidiano e interpretam-se algumas situações-problema por modelos nos quais envolvem equidades matemáticas.

Para a introdução aos conceitos físicos de eletricidade, no sentido de se operacionalizar o uso da instrumentação eletrônica para as medições elétricas, empregase a metodologia abordada por Delizoicov (2005), em função dos problemas e das problematizações, em que seu discurso se pauta, essencialmente, em se utilizar dos tópicos e experimentações adquiridas e se formalizar o contexto com base no modo versado pelo autor, como segue:

\footnotetext{
Este é, sem dúvida, um dos sentidos dos termos problema e problematização. Talvez o que tenha maior relevância para o planejamento do processo de formação dos nossos estudantes, se considerarmos, como Thomas Kuhn (1975), que o conteúdo cognitivo das formulações contidas nos conceitos, modelos, leis e teorias da Física é convenientemente contextualizado, exemplificado e passível de ser apropriado na medida em que o aprendiz se envolva e se dedique à solução de problemas (DELIZOICOV, 2005, p. 1).
}

Neste contexto, a sequência didática proposta para as unidades de aprendizagem das medidas elétricas é: utilização do Alicate-amperímetro, para as medições de tensão e corrente alternadas, para emprego no laboratório/oficina de instalações elétricas; uso 
do voltímetro, em corrente contínua, para a consolidação do conceito da diferença de potencial; uso do amperímetro, também em corrente contínua, com a meta de robustecer a aprendizagem da Lei de Ohm; o manuseio do Ohmímetro para a verificação de continuidade elétrica em instalações de baixa tensão desenergizadas. É importante observar que a instrumentação explorada envolve equipamentos analógicos e digitais.

Portanto, esta disciplina se define como uma das essenciais para a operação destes instrumentos de medição e está postada como das mais importantes para a constituição do PPC do curso FIC em IEBT e a realização de trabalhos envolvendo eletricidade, conforme Braga (2005) versa em seu artigo.

\subsection{Disciplina: Noções de Segurança no Trabalho e Saúde Ocupacional}

Em relação às noções de segurança do trabalho e saúde ocupacional, o enfoque foi dado à conscientização dos riscos inerentes à profissão, orientando os discentes acerca da importância da utilização de equipamentos de proteção individual e coletiva, bem como alguns procedimentos de segurança para a realização das atividades pertinentes à sua profissão a fim de preservar a vida e a saúde do profissional e demais indivíduos, as instalações, as edificações e o meio ambiente.

É fundamental destacar que, ao longo da história, os trabalhadores têm sofrido diferentes consequências provenientes de exposições no ambiente laboral, com elevados reflexos nas esferas econômica, psicossocial e da saúde. Isto se deve à ocorrência de doenças profissionais, do trabalho e acidentes de trabalho. Entretanto, ressalta-se que o conhecimento da dimensão do problema ainda é muito limitado devido às subnotificações (CAVALCANTE et al., 2015). A doença profissional desencadeia-se pelo exercício peculiar da atividade laboral, enquanto a doença do trabalho ocorre em função das condições especiais em que a atividade é realizada, possuindo relação direta com esta. Já o acidente trabalho, pelo conceito legal, ocorre pelo exercício do trabalho, provocando lesões ou alterações funcionais que causem desde a redução temporária da capacidade para o trabalho até a morte (BRASIL, 1991).

$\mathrm{Na}$ atividade laboral de um eletricista, diversos riscos podem estar associados, tais como: quedas, calor, ruído, poeiras diversas, levantamento e transporte manual de peso, postura inadequada dentre outros. O eletricista poderá estar sujeito a cada um 
desses riscos, dependendo do seu ambiente de trabalho e, por isso, torna-se extremamente relevante a consideração de tais problemas e o conhecimento de como conduzir uma tarefa, de maneira segura, quando exposto a esses riscos.

Além disso, é importante destacar que existem riscos inerentes especificamente ao trabalho envolvendo a eletricidade, ou seja, quando o acidentado é vítima de choque elétrico. "Os principais efeitos fisiológicos que uma corrente elétrica (externa) produz no corpo humano são tetanização, fibrilação ventricular, parada cardiorrespiratória e queimadura"(CAMINHA, 1977 apud LOURENÇO; et al, 2007, on-line).

Apesar da criação de medidas de segurança para o trabalho a fim de criar premissas e rotinas para uma atividade segura, muitas pessoas ainda morrem ou ficam gravemente feridas, seja por falta de informação, omissão ou falta de compromisso dos envolvidos nas atividades. Somente no ano de 2016, no estado do Rio de Janeiro, ocorreram 41.859 acidentes do trabalho e entre 2015 e 2016, de acordo com o AET 2016, ocorreram 1.245 acidentes de trabalho em São João de Meriti.

Em relação aos acidentes, envolvendo eletricidade, o Anuário Estatístico de Acidentes de Origem Elétrica 2018 revela que, no período de 2013 a 2017, o número de acidentes fatais envolvendo choque elétrico no Brasil foi, em média, aproximadamente 3,4 vezes maior quando comparado aos não fatais, evidenciando o elevado risco a vida deste tipo de acidente (ABRACOPEL, 2018).

Haja vista o exposto, a disciplina "Noções de Segurança do Trabalho e Saúde Ocupacional" foi elaborada com o intuito de prover aos discentes noções sobre a temática, abordando desde a cultura de segurança, principalmente, para a preservação da vida e saúde do trabalhador, até os principais riscos das atividades do eletricista e algumas medidas de controle. Ademais, os alunos terão a oportunidade de conhecer alguns de seus direitos e deveres quanto trabalhadores atuantes do processo produtivo, assim como algumas obrigações dos empregadores.

[...] a cultura de segurança organizacional consiste em um conjunto de crenças partilhadas que sustentam práticas seguras entre os profissionais que nela trabalham. Tal cultura é marcada pela comunicação aberta, trabalho em equipe, reconhecimento da dependência mútua e a primazia da segurança como uma prioridade em todos os níveis da organização (CRUZ et al., 2018, p. 21). 
A proposta metodológica para esta disciplina consiste em aulas expositivas, envolvendo a utilização de recursos audiovisuais para a exibição de vídeos e fotos a fim de ilustrar e analisar brevemente as possíveis causas e consequências de acidentes, incidentes, doenças decorrentes das atividades laborais, atos e condições inseguras, bem como possíveis alternativas de trabalho seguro e procedimentos de segurança.

Além disso, durante o curso, serão apresentados diversos modelos de equipamentos de proteção individuais e coletivos, como por exemplo, luvas isolantes de borracha e capacetes para o trabalho em instalações elétricas, assim como sinalizações de segurança, além dos tipos de extintores de incêndio e suas aplicações e restrições. Tais recursos objetivam conectar a teoria com a realidade que pode ser encontrada no dia a dia dos futuros profissionais do segmento de elétrica com o intuito de facilitar o entendimento do estudo do ambiente e dos riscos originados do processo produtivo e suas principais medidas de controle.

Durante as aulas expositivas, ocorrerão breves interpretações de leis e normas pertinentes a segurança e saúde no trabalho, abrangendo aspectos pontuais das legislações trabalhistas e previdenciária. Em complemento, debates sobre os assuntos estudados serão valorizados para proporcionar melhor fixação e reflexão por parte dos discentes.

\footnotetext{
Uma metodologia na perspectiva dialética baseia-se em outra concepção de homem e de conhecimento. Entende o homem como um ser ativo e de relações. Assim, entende que o conhecimento não é "transferido" ou "depositado" pelo outro (conforme a concepção tradicional), nem é "inventado" pelo sujeito (concepção espontaneísta), mas sim que o conhecimento é construído pelo sujeito na sua relação com os outros e com o mundo (VASCONCELLOS, 1992, on-line).
}

Além dos debates, foram criados exercícios de fixação para todos os assuntos que serão abordados, cuja finalidade é obter um feedback do aprendizado dos alunos, podendo, adicionalmente, ser utilizado como forma de avaliação formativa.

Quanto ao tema "Cultura de Segurança", além de debates sobre notícias de acidentes, foi planejada uma dinâmica de grupo para provocar reflexão sobre a importância da segurança e da saúde na vida dos discentes, tanto no trabalho quanto na vida pessoal. A atividade basicamente consiste na hierarquização de diversos itens que, geralmente, são importantes na vida das pessoas, como por exemplo, dinheiro, amizade 
e reconhecimento profissional e uma análise sobre a relevância da segurança e saúde dentro destes contextos.

Além disso, pretende-se participar aos discentes sobre a existências de diversos documentos relacionados a saúde e segurança comumente encontrados nas empresas, como por exemplo, Mapa de Riscos, Análise Preliminar de Riscos (APR), Programa de Prevenção de Riscos Ambientais (PPRA) e o Programa de Controle Médico de Saúde Ocupacional (PCMSO). Apesar de diversas Normas Regulamentadoras (NR), relativas à segurança e medicina do trabalho serem abordadas pontualmente, ênfase será dada a NR 10 - Segurança em Instalações e Serviços em Eletricidade por se tratar de uma das referências centrais para o trabalho do eletricista.

\subsection{Disciplina: Formação Geral}

Complementando o quadro de formação do eletricista, o curso FIC, em IEBT, ainda oferece as disciplinas que fazem parte do núcleo comum. Essas disciplinas objetivam integralizar a formação geral do aluno, assim como prover conhecimentos adicionais à área de formação do curso (e.g. inglês instrumental, redação técnica, sociologia e empreendedorismo). As disciplinas de Empreendedorismo e Trabalho, Ética e Cidadania, cujas cargas horárias são 27 horas, foram escolhidas estrategicamente, pois elas complementam a formação do discente no sentido de capacitarem-no para melhor exercer sua cidadania, reforçar sua cultura e identidade profissional, bem como conhecer alguns conceitos e técnicas para empreender no mercado de trabalho.

\subsection{Disciplina: Trabalho, Ética e Cidadania}

Além da introdução aos conceitos de ética, cidadania e democracia, esta disciplina busca o debate acerca do espaço do profissional eletricitário no mercado de trabalho e o seu fazer ético nas relações com os clientes, a fim de que os discentes se tornem indivíduos mais conscientes do seu papel, direitos civis, políticos e sociais.

É importante destacar que, em decorrência da reestruturação da produção, globalização dos mercados financeiros e das economias, desregulamentação e abertura 
mercadológica, com ruptura das barreiras protecionistas, ocorreram vastas mudanças do modelo econômico, atingindo, aceleradamente e de forma diferenciada, muitos setores da população trabalhadora. Tais mudanças ocasionaram permanentes incertezas e aprofundamento das desigualdades sociais, bem como a exclusão social (GOMEZ; THEDIN-COSTA, 1999).

No caso brasileiro, observa-se progressiva pauperização que envolve inclusive trabalhadores integrados ao mercado formal de trabalho, gerando insegurança, instabilidade e precariedade nos vínculos laborais e desestruturação/reconstrução de identidades geradas em torno do trabalho (GOMEZ; THEDIN-COSTA, 1999, p. 411).

As atividades laborais devem apresentar seis características para motivar o comprometimento de seus realizadores: a variedade e o desafio, a aprendizagem contínua, margem de manobra e autonomia, reconhecimento e apoio, um futuro desejável e uma contribuição social que faça sentido. Nesse último, destaca-se que o trabalho deve permitir a junção entre seu exercício e as consequências sociais relacionadas ao fato, contribuindo, dessa maneira, para a construção da identidade social do indivíduo, sendo que, nesse âmbito, o trabalho reconhece o prazer de contribuir para a sociedade (EMERY, 1964; EMERY 1976; TRIST, 1978 apud MORIN, 2001).

Então, apesar da crescente precariedade dos vínculos laborais, é importante que o trabalhador se reconheça no produto do trabalho que realiza e entenda a importância deste para o seu contexto. A disciplina Trabalho, Ética e Cidadania busca trabalhar a temática, além de explorar conceitos, como por exemplo, papéis sociais, controle social, socialização, etnocentrismo e relativismo cultural. Rocha (1994) definiu etnocentrismo como um ponto de vista do mundo, em que o grupo no qual o indivíduo pertence é considerado central e os demais grupos são pensados e sentidos por ele, através de seus próprios modelos, valores e definições.

Quanto à metodologia de ensino desta disciplina, buscou-se fornecer aos alunos debates contextualizados sobre o trabalho, considerando que a crítica e a análise são pilares importantes aliadas à formação técnica, contribuindo para a complementação do futuro profissional da área de elétrica. Para fomentar tais discussões, ao longo do curso, foram planejados debates a serem realizados em sala de aula sobre diversos fragmentos textuais, a fim de incitar reflexões coletivas e individuais sobre os temas propostos. 
Com a finalidade de sistematizar o conteúdo e descomplexificar associações entre as informações relevantes, serão utilizados mapas mentais. Além disso, este recurso visa clarear possíveis causas e consequências dos eventos discutidos. Como exercício, os discentes serão sugeridos a lerem conteúdos complementares sobre os temas abordados em sala de aula e refletirem sobre suas ideias. O estudo da ética e das relações interpessoais no trabalho dar-se-á através de estudos de casos reais e hipotéticos, sugerindo análises sobre possíveis alternativas para as condutas a serem tomadas. Outrossim, pretende-se utilizar de dinâmicas de grupos para discutir diversos temas como racismo, preconceito e estereótipo.

Salienta-se que a escolaridade exigida para este curso é o quinto ano do ensino fundamental e que, neste nível, os discentes não estudam sociologia ou filosofia no ensino regular, temas que, de acordo com a LDB/1996, são abordados no ensino médio. Este nível de ensino, dentre outras finalidades, preconiza o aperfeiçoamento do discente, incluindo formação ética e o desenvolvimento do pensamento crítico (BRASIL, 1996). Portanto, no curso em questão, para além do exposto, pretende-se iniciar uma contribuição para o desenvolvimento do senso crítico do aluno.

\subsection{Disciplina: Empreendedorismo}

A abordagem do Empreendedorismo, neste curso, tem como enfoque o desenvolvimento da proficiência dos discentes quanto às habilidades de inovação e gestão de pequenos negócios, bem como estimular o desenvolvimento socioeconômico local e a promoção de negócios éticos e sustentáveis.

Neste contexto, cabe apontar que, atualmente, o mundo dos negócios está cada vez mais competitivo e sofre mudanças constantemente. Por tanto, para enfrentar estas mudanças e manter-se competitivo no mercado, é necessário utilizar-se cada vez mais do empreendedorismo como estratégia de negócios. É preciso ter coragem para enfrentar desafios e escolher novos caminhos de forma consciente, ser criativo e assumir os riscos de forma controlada (CUSTÓDIO, 2011).

Assim, segundo Menezes (2018), o empreendedor é o indivíduo de iniciativa que promove o empreendimento a partir de um comportamento criativo e inovador, que sabe transformar contextos, estimular a colaboração, criar relacionamentos pessoais, gerar 
resultados, fazendo o que gosta de fazer, com entusiasmo, dedicação, autoconfiança, otimismo e necessidade de realização.

Não basta deter apenas as habilidades técnicas para uma formação mais completa do profissional do setor de eletricidade, é preciso que eles desenvolvam o comportamento empreendedor, conheçam as condições para se montar um negócio e as ferramentas para fidelizar uma cartela de clientes pela satisfação e percepção de um bom serviço prestado, pois eles terão também a possibilidade de atuar como profissionais autônomos e, como tais, enfrentar o mercado. Segundo Longenecker et al., (1997), eles devem ter visão e percepção para identificar as oportunidades, desenvolver um estereótipo comum de um empreendedor que enfatiza características como uma enorme necessidade de realização, uma disposição para assumir riscos moderados e uma forte autoconfiança.

A partir disso, a disciplina Empreendedorismo pretende desenvolver a capacidade empreendedora na área de gestão, com ênfase na prática empreendedora, nas técnicas de identificação de aproveitamento de oportunidades, na aquisição e no gerenciamento dos recursos necessários ao negócio, fazendo uso de metodologias que priorizam técnicas de criatividade e inovação. Além disso, temas como marketing pessoal, planejamento, estratégia e gestão de pequenos negócios, plano de negócios, noções de legislação e contabilidade aplicadas ao microempreendedor individual serão abordados.

Essas ferramentas, no campo dos negócios, poderão contribuir para o desenvolvimento do discente egresso do FIC IEBT, fornecendo possibilidades de atuarem não somente com empregados, como por exemplo, na construção civil ou indústria, mas como provedores dos seus próprios negócios, administrando suas próprias empresas, criando a sua própria história, com a criação de valores implementando ideias por meio da aplicação da criatividade, capacidade de transformar e do desejo de tomar aquilo que comumente se chamaria de risco (LEITE, 2000).

Para cumprir o conteúdo programático, a metodologia a ser implementada será composta de aulas expositivas, com a utilização de recursos audiovisuais. Ao longo do curso, a turma será dividida em grupos e esses serão estimulados a pensarem e a desenvolverem um modelo de negócio, relacionado à área de eletricidade. Como método avaliativo, deverão ser apresentados, ao fim do curso por cada grupo, um 
trabalho sobre os seus respectivos Planos de Negócios. A esse trabalho, serão acrescentadas também as avaliações individuais: assiduidade, participação e desenvolvimento.

O conjunto dessas disciplinas foi considerado como essencial para que o egresso do curso de IEBT tivesse uma formação técnica e geral, qualificando-o para o trabalho em sistemas elétricos de baixa tensão tanto na indústria da construção civil, quanto numa carreira autônoma, sendo gestor do seu próprio negócio.

\section{CONCLUSÃO}

Foram mostradas as particularidades do desenvolvimento do Plano Político de Curso na modalidade de Formação Inicial e Continuada em Instalações Elétricas Prediais, observando-se o seu processo de concepção, as habilidades pretendidas para os discentes, bem como os principais segmentos de mercados que eles estariam aptos para trabalhar, haja vista a formação oferecida. Constatou-se, de acordo com o censo amostral relativo ao trabalho de 2010, que a cidade de São João de Meriti possui número de eletricitários relativamente baixo, quando comparação às cidades vizinhas. Portanto, a qualificação oferecida através deste curso está de acordo com a aproximação dos objetivos dos Institutos Federais de Educação e a realidade local, uma vez que existe necessidade de tais profissionais na região, assim sendo importante no seu contexto socioeconômico.

Como foi visto, as disciplinas foram elaboradas para atuarem de maneira orgânica no curso, levando em consideração o arcabouço técnico aliado às práticas seguras de trabalho, capacidade empreendedora e valorização da ética, senso crítico e compreensão da importância do trabalho para a sociedade. Quanto a metodologia, contribuiu-se através de propostas metodológicas diversificadas a fim de estimular o processo de aprendizagem, bem como facilitar a compreensão dos conteúdos de maneira lúdica e prática.

Devido à instabilidade política e escassez de recursos comentadas, brevemente, neste artigo, houve impossibilidade da efetivação da compra dos itens necessários para cumprimento do curso em consonância com o PPC proposto. Tal fato direcionou a equipe técnica a buscar outras soluções; contudo, durante meses, não foi possível 
montar por completo o ambiente pensado para realização das aulas práticas. Somente em 2018, material suficiente foi recebido para conclusão da montagem do laboratório.

É proposto como prosseguimento desta pesquisa os seguintes assuntos:

- Análise das peculiaridades e dificuldades do desenvolvimento do laboratório de instalações elétricas, conjugado com a sala de aula, considerando-se as questões de segurança;

- Análise quantitativa e/ou qualitativa acerca dos resultados obtidos a partir dos alunos frente às metodologias de ensino empregadas;

- Análise dos impactos de inclusão do conteúdo de matemática básica dentro da disciplina de Medidas Elétricas e reflexão sobre a necessidade da criação de uma disciplina separada ou aumento de carga horária.

\section{REFERÊNCIAS}

AMARAL, É. M. H.; ÁVILA, B; ZEDNIK, H; TAROUCO, L. Laboratório Virtual de Aprendizagem: Uma Proposta Taxonômica. Revista Novas Tecnologias na Educação,on-line, Rio Grande do Sul, v. 9, n. 2 2011. Disponivel em: $<:$ https://seer.ufrgs.br/renote/article/view/24821>. Acesso: 04/01/2019.

ASSOCIAÇÃO BRASILEIRA DE CONSCIENTIZAÇÃO PARA OS PERIGOS DA ELETRICIDADE - ABRACOPEL. Anuário estatístico brasileiro dos acidentes de origem elétrica. Disponível em: < http://a7d4083.contato.site/inscricaoanuario-2018>. Acesso em: 28 dez. 2018.

BRAGA, N. C. O multímetro nas instalações elétricas (EL038). 2005. Disponível em: $\quad<$ http://www.newtoncbraga.com.br/index.php/instalacoes-residenciais/6646-omultimetro-nas-instalacoes-eletricas-el038>. Acesso em 23 de dez. 2018.

BRAIT, L. F. R., MACEDO, K. M. F., SILVA, F. B., SILVA, M. R., \& SOUZA, A. L. R. A relação professor/aluno no processo de ensino e aprendizagem. Itinerarius $\begin{array}{llll}\text { Refectionis, Jataí, } & \text { v.8, } & \text { n.1, }\end{array}$ 2010. <https://www.revistas.ufg.br/rir/article/viewFile/40868/20863>. Acesso em 28 de dez. 2018.

BRASIL. Lei $n^{\circ}$ 8.213, de 24 de julho de 1991. Dispõe sobre os Planos de Benefícios da Previdência Social e dá outras providências. Brasília, 1991. Disponível em: <http://www.planalto.gov.br/ccivil_03/LEIS/L8213cons.htm>. Acesso em 14 dez. 2018.

BRASIL. Lei n. 9394, de 20 de dezembro de 1996. Estabelece as diretrizes e bases da educação nacional. $\quad$ Brasília, $1996 . \quad$ Disponível em:<http://www.planalto.gov.br/ccivil_03/leis/19394.htm>. Acesso em: 12 dez. 2018. 
BRASIL. Lei n. 11.892, de 29 de dezembro de 2008. Institui a Rede Federal de Educação Profissional, Científica e Tecnológica, cria os Institutos Federais de Educação, Ciência e Tecnologia, e dá outras providências Brasília, 2008. Disponível em:<http://www.planalto.gov.br/ccivil_03/_Ato2007-2010/2008/Lei/L11892.htm>. Acesso em: 12 dez. 2018.

BRASIL. Lei n. 12.513, de 26 de outubro de 2011. Institui o Programa Nacional de Acesso ao Ensino Técnico e Emprego (Pronatec) Brasília, 2011. Disponível em:<http://www.planalto.gov.br/ccivil_03/_Ato2011-2014/2011/Lei/L12513.htm>.

Acesso em: 12 dez. 2018.

BRASIL. Secretaria de Previdência. Ministério da Economia. Anuário. Brasília, 2018. Disponível em: <http://www.previdencia.gov.br/2018/04/anuario-acidentes-de-trabalhoapresentam-queda-de-7-em-2016/>. Acesso em 24 ago. 2019.

CAPUANO, F. G; MARINO, M. A. M. Laboratório de eletricidade e eletrônica. 24. ed. São Paulo: Érica, 2007. 309.

CAVAlCANTE, C. A. A.; COSSI, M. S.; COSTA, R. R. O.; MEDEIROS, S. M.; MENEZES, R. M. P. Análise crítica dos acidentes de trabalho no Brasil. Revista de Atenção à Saúde. São Caetano do Sul, v. 13, n. 44, p. 100-109, 2015. Disponivel em: <http://seer.uscs.edu.br/index.php/revista_ciencias_saude/article/view/2681> . Acesso em: 02 de Jan. 2019.

CONSELHO NACIONAL DAS INSTITUIÇÕES DA REDE FEDERAL DE EDUCAÇÃO PROFISSIONAL, CIENTÍFICA E TECNOLOGICA- CONIF. Orçamento 2017 põe em risco funcionamento das instituições da Rede Federal. De 16 de agosto de 2016. Disponível em: < http://portal.conif.org.br/br/component/content/article/100-comunicacao/609orcamento-2017-poe-em-risco-funcionamento-das-instituicoes-da-redefederal?Itemid=609> Acesso em : 06 de Fev. 2019.

COSTA, L. R.; TOMASI, A. P.N. O canteiro de obras é escola. Formação de qualificação profissional na construção civil. Revista Teoria e Sociedade, n.17, de julho-dezembro de 2009.

COSTA, S; COSTA, A. Perfil dos educandos da primeira turma do curso PROEJA-FIC do Instituto Federal de Santa Catarina, Câmpus Araranguá - SC. EJA em debate, Florianópolis, ano 4, n. 6, dez. 2015. Disponível em: <https://periodicos.ifsc.edu.br/index.php/EJA >. Acesso em 29 de jan. de 2019.

CRUZ, E. D. A.; ROCHA, D. J. M.; MAURICIO, A. B.; ULBRICH, F. S.; BATISTA, J.; MAZIERO, E. C. S. Cultura de segurança entre profissionais de saúde em hospital de ensino. Cogitare Enfermagem, Curitiba, v. 23, n.1, p. 20-29, 2018. Disponível em : <https://revistas.ufpr.br/cogitare/article/view/50717> . Acesso em 02 de jan. 2019. 
CUSTÓDIO, T. P. A importância do empreendedorismo como estratégia de negócio. 2011 60f. Trabalho de Conclusão de Curso( Administração). Unisalesiano. Lins, SP.

DELIZOICOV, D. Problemas e Problematizações. In: Pietrocola, M. (Org.). Ensino de Física: conteúdo, metodologia e epistemologia em uma concepção integradora. Florianópolis: UFSC, p. 125-150, 2005. Disponível em: $<$ https://edisciplinas.usp.br/pluginfile.php/87874/mod_resource/content/2/Problemas_pr oblematizacao.pdf > Acesso em 20 de dez. 2018.

FILHO, W. M; PONTES, J. C. A. de. O Panorama Atual dos Acidentes de Trabalho na Construção: Uma Análise a Partir do Anuário Estatístico da Previdência Social Triênio 2013 a 2015. Revista Científica Multidisciplinar Núcleo do Conhecimento. Ano 03, Ed. 02, Vol. 04, pp. 19-29, Fevereiro de 2018. ISSN: 2448-0959.

FOLGADO, R. M. Práticas docentes cm cursos de formação inicial e continuada (FIC) do Pronatec. 2015. 141 f Dissertação (Mestrado) - Centro Universitário UNA, Programa de Pós Graduação cm Gestão Social, Educação e Desenvolvimento Local. Belo Horizonte.

GOMEZ, C. M.; THEDIM-COSTA, S. M. F. Precarização do trabalho e desproteção social: desafios para a saúde coletiva. Ciência \& Saúde Coletiva, Rio de Janeiro, v. 4, n.2, p. 411-421, 1999. Disponível em: 〈http://www.scielo.br/pdf/csc/v4n2/7123.pdf >. Acesso em 05 de jan. de 2019.

INSTITUTO BRASILEIRO DE GEOGRAFIA E ESTATÍSTICA. Censo 2010. Rio de Janeiro: IBGE, 2011. Disponível em: <http://censo2010.ibge.gov.br/>. Acesso em 23/10/2017.

LEITE, E. O Fenômeno do Empreendedorismo. Recife: Bagaço, 2000. Disponível em: <http://portal.conif.org.br/br/component/content/article/100-comunicacao/609orcamento-2017-poe-em-risco-funcionamento-das-instituicoes-da-redefederal? Itemid=609>Acesso em 02 de jan. 2019.

LONGENENECKER, J. G.; MOORE, C. W.; PETTY,J.W. Administração de pequenas empresas: ênfase na gerência empresarial. São Paulo: Makron Books, 1997. 868p.

LOURENÇO ,S. R. SILVA, T. A. F.; FILHO, S. C. S. Um estudo sobre os efeitos da eletricidade no corpo humano sob a égide da saúde e segurança do trabalho. Exacta. São Paulo, v.5, n.1, p. 135-143, 2007.

MENEZES, L.C.M. Gestão de Projetos. 4 ed. São Paulo: Atlas, 2018. 336p.

MORIN, E. M. Os sentidos do trabalho. Revista de Administração de Empresas, São Paulo, v. 41, n. 3, p. 8-19, 2001. 
OlIVEIRA, L. A. C; MIRANDA, E. A. Políticas de Educação Profissional: Algumas reflexões sobre o PRONATEC. IV Colóquio Nacional e I Colóquio Internacional - A produção do conhecimento em educação profissional. Natal, 2017. 10 p.

PACHECO, E. M. Os institutos federais: uma revolução na educação profissional e tecnológica. IFRN, 2010, 28p.

PICCHI, F. A.; AGOPYAN, V. Sistema da qualidade: uso em empresas de construção de edifícios. 1993. Tese de Doutorado em Engenharia Civil e Urbana - Escola Politécnica da Universidade de São Paulo, 1993;

PINTO, J. M., Tendência na incidência de acidentes e doenças de trabalho no Brasil: aplicação do filtro Hodrick- -Prescott. Revista Brasileira de Saúde Ocupacional. 2017, vol. $42 . \quad$ Disponível em: <http://www.redalyc.org/articulo.oa?id=100550852010>. Acesso em 22 de jan. 2019.

PPC FIC Eletricista Baixa Tensão, IFRJ, São João de Meriti. 2017

PPC FIC Eletricista Instalador Predial Baixa Tensão, IFPA, Tucuruí. 2013

PPC FIC Eletricista Instalador Predial Baixa Tensão, IFRN, Natal. 2012

PPC FIC Eletricista Predial de Baixa Tensão, IFSC, São Carlos. 2015.

ROCHA, E. P. G. O que é etnocentrismo. 11. Ed. São Paulo: Brasiliense, 1994. ISBN 85-11-01124-2.

SEGUNDO, M. S; MARTINS, A. R. Os ataques aos Institutos Federais: a restauração neoliberal radical no governo Temer. Universidade e Sociedade. ANDESSN. (2018)

SOUZA, M. L. H. de. Avaliação da efetividade dos principais cursos FIC Pronatec do Instituto Federal de Santa Catarina: benchmarking com cursos técnicos de longa duração. 2016. 74 f. Dissertação (Mestrado Profissional em Gestão Pública) Universidade de Brasília (UnB). Brasília, 2016.

SOUZA, U. E. L. de. Como Aumentar a eficiência da mão-de-obra: manual de gestão da produtividade na construção. São Paulo: Pini, 2006. 100p.

VASCONCELLOS, C. S. Metodologia dialética em sala de aula. Revista de Educação AEC. Brasília, v.21 n.83, p.28-55, 1992. 